\section{Reading and writing}

01-124 Chung, Jenny S. L. (Hong Kong Inst. of Ed., China; Email: jenny@ied.edu.hk). Signals and reading comprehension - theory and practice. System (Oxford, UK), 28, 2 (2000), 247-59.

This paper explores the relationship between signals, coherence and reading comprehension, and particularly whether signals contribute to comprehension at a local (microstructure) or a global (macrostructure) level. It describes an investigation of the effects of logical connectives and paragraph headings on reading comprehension among 577 Hong Kong Secondary 6 students learning English as a Second Language. An English reading comprehension test was used to allocate participants into one of the three performance groups: High, Medium and Low. The test instruments used to discriminate between the different groups contained 'normal' signals. In the signal studies, four versions of authentic text were produced. Version 1 was a non-signalled passage.Versions 2, 3, and 4 were embedded with logical connectives, paragraph headings and these two signals in combination. All four versions had the same content and the same level of difficulty. Results show that those poorest in reading comprehension (Low Performance Group) benefited from signals during the reading. All signals contributed to reading comprehension except for logical connectives, which did not aid microstructure understanding. The discussion of results includes implications for the teaching of reading to poor readers.

\section{1-125 De Ridder, Isabelle (U. of Antwerp}

(U.I.A.), Belgium; Email: deridder@uia.ua.ac.be). Are we conditioned to follow links? Highlights in CALL materials and their impact on the reading process. Computer Assisted Language Learning (Lisse, The Netherlands), 13, 2 (2000), 183-95.

This article argues the case for evaluation of some of the additional features of Computer Assisted Language Learning (CALL) materials designed to enhance second-language reading comprehension. The experiment undertaken - involving 17 undergraduate Dutch native speakers reading French texts - carefully analysed the effects of highlights indicating a link towards dictionary definitions on the second language reading process. The findings demonstrate that randomly highlighting words in a text on screen influences the amount of vocabulary incidentally learned by the reader. Moreover, the results strongly indicate that reading in a highlighted or marked setting is fundamentally different from reading a text in an unmarked condition. This calls for reflection on how to present the learner with the enhancements of CALL.

01-126 Flowerdew, John (City U. of Hong Kong). Discourse community, legitimate peripheral participation, and the nonnative-English-speaking scholar. TESOL Quarterly (Alexandria, VA, USA), 34, 1 (2000), 127-50.

This article presents a case study of a nonnativeEnglish-speaking scholar from Hong Kong and his experience in publishing a scholarly article in an international refereed journal on his return from doctoral study in the United States. The investigation is presented as a contribution to the important study of what it means to be a non-anglophone researcher seeking international publication in English but living and researching in a non-anglophone country. The article applies elements of social constructivist theory: the data are interpreted in view of how the scholar learns the conventions of the discourse community through legitimate peripheral participation. The author draws implications for how TESOL professionals might contribute to this type of English language learning, which he argues is critical to the success of many nonnative-speaking scholars.

01-127 Hammadou, Joann (U. of Rhode Island, Kingston, USA; Email: joannh@uri.edu).The impact of analogy and content knowledge on reading comprehension: what helps, what hurts. The Modern Language Journal (Malden, MA, USA), 84, 1 (2000), 38-50.

Little research has been carried out comparing reading comprehension of analogies between first language (L1) and second language (L2) readers, despite the fact that many L1 reading experts believe that analogies facilitate reading comprehension. This article explores the impact of analogies and prior content knowledge on reading comprehension of expository texts by both L1 and L2 readers. Written recall protocols from approximately 163 participants were analysed for two texts. Readers were university students of either French or English as a foreign language and were categorised according to level of proficiency and amount of prior content knowledge. Participants read either an analogy or non-analogy version of two separate passages in either their L1 or L2. Analogy had a debilitating effect on comprehension regardless of learner group on the first text and no significant effect on the second text. Level of proficiency and prior content knowledge were significantly related to reading comprehension.

\section{1-128 Kramsch, Claire (U. of California}

Berkeley, USA; Email: ckramsch@

socrates.berkeley.edu), A'Ness, Francine and

Lam, Wan Shun Eva. Authenticity and authorship in the computer-mediated acquisition of $L 2$ literacy. Language Learning and Technology (http://llt.msu.edu/), 4, 2 (2000), 78-104.

This paper examines what becomes of the two tenets of communicative language teaching - authenticity of the input and authorship of the language user - in an electronic environment. A brief review of relevant research in textually-mediated second language acquisition is followed by an analysis of two cases of computer-medi- 
ated language learning: (a) the construction of a multimedia CD-ROM by American college learners of Spanish, and (b) the use of Internet relay chat by a Chinese high school learner of English. The authors discuss what kind of second language (L2) literacy the students acquire through the computer medium. They find that a communicative approach based on the use of authentic texts and on the desire to make the learners author their own words has been changed by the physical properties of the electronic medium and the students' engagement with it. The authors conclude that, as one moves from print literacy to electronic literacy, the key notions of authenticity and authorship should be reframed in terms of agency and identity, and they speculate that computer technology may restore the value of role play, theatricality, fictionalisation in language learning.

\section{1-129 Kupetz, Rita (Universität Hannover,} Germany). Wortschatzprofile von Lernertexten als Indikator von Schreibkompetenz - Zur Korrelation zwischen computergestützter Wortschatzanalyse und einem 'kommunikativen Gesamteindruck'. VVocabulary profiles of learner texts as an index of writing ability - on the correlation between computer-assisted vocabulary analysis and a 'communicative overall impression'.] Fremdsprachen und Hochschule (Bochum, Germany), 58 (2000), 74-93.

This article outlines a study at the author's institution into the relevance of vocabulary profiles for the description of written learner texts. The data were collected from university courses for students of English and from German secondary-school learners of English. The linguistic description of the data is contrasted with native-speaker (i.e., authentic) texts which are taken as expressing a norm. Frequency profiles for learner texts and native-speaker texts were formulated with the help of software. The author assumes that frequency profiles are an expression of lexical richness or poverty and can thus be seen as an index of competence in writing. This hypothesis is checked against a 'communicative overall impression' which a native speaker received from the learner texts. Three text types were examined in this study: book review, business letter and summary. The text type summary was the centre of a more comprehensive evaluation which is included in the appendix.

\section{1-130 Li, Yili (Hong Kong Baptist U.; Email:} yili9098@hkbu.edu.hk). Linguistic characteristics of ESL writing in task-based email activities. System (Oxford, UK), 28, 2 (2000), 229-45.

This study investigated the efficacy of integrating taskbased email activities into a process-oriented English as a Second Language (ESL) writing class. In particular, it examined the linguistic characteristics of 132 pieces of email writing by ESL students in tasks that differed in terms of purpose, audience interaction and task structure. The analysis focused on the linguistic features of the students' email writing at different levels, i.e., syntactic complexity, lexical complexity and grammatical accuracy. Computerised text analysis programs were used to ensure internal consistency of the linguistic analysis. Statistical analysis of the results using the repeated measures analysis of variance and post hoc contrast tests showed significant syntactic, lexical and grammatical differences in the students' email writing of the different tasks. Specifically, in email tasks involving audience interaction, students tended to produce syntactically and lexically more complex texts, and in tasks which allowed students self-selection of topics and content, students also tended to use more complex sentences and richer and more diverse vocabulary. However, an interesting trade-off effect was observed between linguistic complexity and grammatical accuracy in the students' email writing, indicating the complexity of the second language writing process. The study is seen as providing pedagogical implications for designing effective email tasks for enhancing second language writing development.

\section{1-131 Loewy, Dana and Vogt, Gayle}

(California State U., Fullerton, USA). Sharing the responsibility of communication. Journal of Language for International Business (Glendale, AZ, USA), 11, 1 (2000), 83-92.

The present authors developed a Management Communication class for foreign-born students at their institution who score below 4.0 on the Graduate Management Admission Test (GMAT) Analytical Writing Assessment (AWA). This article looks at the AWA, its place in classifying graduates, and its use in graduate and management communication. It also offers insights provided by Contrastive Rhetoric, the linguistic discipline that focuses on the language and cultural challenges students face; and, based on these, proposes recommendations for a greater understanding of international students and the improvement of graduate writing. Specifically, the authors propose several curriculum improvements for non-native speakers: a writing centre, integrated oral presentations, rigorous but insightful grading, and mentoring programmes.

\section{1-132 Maya Khemlani, David and Norazit, Lynne (U. of Malaya, Malaysia; Email:} mayadavid@geocities.com). Selection of reading texts: moving beyond content schema. Literacy Across Cultures (Fukui, Japan), 3, 2 (2000), 11-17.

Schema theory proposes that readers possess different conceptual frameworks, called schemata, which they bring to the reading of a text and which they use to make sense of what they read. The first part of this paper suggests that unfamiliar material or text can be used successfully in the classroom and offers ways for teachers to select texts and provide readers with adequate support before and during the reading process. It is also suggested that teachers make use of interesting and simply written genre as in oral discourse or autobiographies. The second section focuses on the approach 
to text selection and uses a sample narrative to show how a text dealing with an unfamiliar, even unknown, topic can be exploited with the target reader. Other pre-teaching activities are described which aim to provide cultural background information to aid the student. It is concluded that teachers should not be constrained to select text which matches the content knowledge of the students and that they should move beyond known schemata in selecting texts.

\section{1-133 Murray, Denise E. (NCELTR, Macquarie} U., Sydney, Australia; Email: denise.murray@ mq.edu.au). Changing technologies, changing literacy communities? Language Learning and Technology (http://lt.msu.edu/), 4, 2 (2000), 43-58.

This article takes a critical historical perspective on the relationship between technologies and literacies. The author argues on the one hand that technologies are not at the root of social or cognitive changes (as people commonly assume), but rather that they amplify particular values and beliefs that a society already holds. On the other hand, it is argued that, if all tools reflect social values and practices, their full social meaning is generally not evident when they are first introduced, but develops only through their use in society. These are taken as starting points in a discussion of the role of computer technology in society in general, and its implications for literacy in particular. At the heart of the argument is a conviction that the outcomes of computer-based literacy will be neither inevitable nor ideologically neutral, and that educators hold a special responsibility to understand and to help shape the ideological climate that will influence how computers are used in people's lives.

01-134 Richards, Cameron (Nanyang Tech. U., Singapore; Email: crichards@nie.edu.sg). Hypermedia, internet communication, and the challenge of redefining literacy in the electronic age. Language Learning and Technology (http://lt.msu.edu/), 4, 2 (2000), 59-77.

This article takes a theoretical perspective on shifts in typologies of discourse, with a particular emphasis on hypermedia and computer-mediated communication. The author argues that hypermedia models of electronic discourse which adopt an informational focus are too narrowly construed and are plagued by internal contradictions. In an attempt to move beyond strict dichotomies (e.g., spoken vs. written language; image vs. text; immediacy vs. distantiation; social communion vs. alienation) in the development of typologies of network communication, the author draws on the work of Paul Ricoeur to propose a broader, communicationsbased framework for the analysis of electronic discourse. Within this perspective, a dialogical 'rhetoric of design' is proposed (as well as practised in the article) which would help to view literacy as a dialogical process (whatever the mode and medium of communication) and to better understand the rhetorical uses and abuses of electronic media.
01-135 Rosowsky, Andrey (Kimberworth Comprehensive School, Rotherham, UK). Reading and culture: the experience of some of our bilingual pupils. English in Education (Sheffield, UK), 34, 2 (2000), 45-53.

This article explores the nature of reading for meaning as it affects the reading abilities of secondary-age bilingual pupils. It briefly discusses cultural schemata theories which seek to account for the influence of culture on the reading process, and reports on a small-scale study designed to improve the reading comprehension of a small group of bilingual British Asian pupils. The study examined the effect on comprehension of a minimal culturally-based modification of a text. Results suggested that with very little modification, the text was made more meaningful for readers. The study illustrates the importance of cultural determinants on the understanding of text and suggests possible strategies for overcoming potential textual difficulties.

\section{1-136 Schmidt, Claudia (Albert-Ludwigs-}

Universität Freiburg, Germany; Email:

Schmicl@freiburg.de). Arbeitsgedächtnis und

fremdsprachliches Leseverstehen. [Working

memory and foreign language reading

comprehension.] Zeitschrift für

Fremdsprachenforschung (Bochum, Germany), 11 1 (2000), 83-101.

Two propositions form the basis of many text comprehension models: that (reading) comprehension capacity is limited by the capacity of the working memory, which can only hold a limited number of propositions, and that working memory is individually varied. Central to the present paper is whether the (individual) capacity of working memory determines reading comprehension competence in a foreign language. Prior to a discussion of the recent literature on the subject, the author outlines the individual components of working memory (according to Baddeley's model) as well as their significance for the process of reading comprehension and how their competence may be measured, including the dual-task method and the psychometric approach. Schmidt then focuses on the relationship between (individual) working memory capacity and competence in foreign language reading comprehension - measured against native speaker competencies. The paper concludes with a discussion of the pedagogical implications for reading skills in a foreign language.

01-137 Suh, Jae-Suk (Korea U.). The effects of reading instruction on reading attitude and reading process by Korean students learning English as a second language. Applied Language Learning (Monterey, USA), 10, 1/2 (1999), 77-122.

This article reports on a study designed to investigate the effects of reading instruction on the reading attitude and reading process of Korean students learning English as a Second Language (ESL). Participants in the study were two Korean learners of ESL who had 
received reading instruction for an average of seven years in which vocabulary and grammatical knowledge were emphasised - they focused heavily on decoding words and analysing sentence structure. Interviews were conducted to determine reading attitudes, while think-aloud procedures were used to examine reading process. Content analyses of the resulting data suggest that participants' attitudes towards reading in English clearly reflect the way they were taught reading (heavy emphasis on memorising vocabulary, decoding words and analysing sentence structures for the interpretation of a text). Concerning the reading process, however, the effect of reading instruction on the use of reading strategies was less clear. Despite participants' predominant use of bottom-up processing, this was not thought to indicate a direct, exclusive relationship between the reading strategies they employed and their reading instruction history, since there are many confounding factors at work (e.g., language proficiency and second language instruction, among others) which influence the use of reading strategies. The article concludes with some suggestions for the teaching of reading in English as a Foreign Language classrooms in Korea.

01-138 Thorson, Helga (U. of Arkansas, USA; Email: hmthorson@ualr.edu). Using the computer to compare foreign and native language writing processes: a statistical and case study approach. The Modern Language Journal (Malden, MA, USA), 84, 1 (2000), 155-70.

Writing process research has attracted significant attention in English composition studies. However, much less research exists on the relationship between foreign language (FL) and first language (L1) writing processes. This study focuses on whether university students studying an FL (in this case German) at an American university use the same processes and writing strategies in FL and L1 writing in two different genres (letter and article). Using a computerised tracking device, individual writing sessions were analysed through statistical techniques and individual case studies. Statistical results provided evidence that students wrote less, but revised more, when writing in the FL than in the L1. In their L1, students tended to revise less in the letter genre than when writing an article. The author advocates using the computer for writing process research, given that it is an unobtrusive and efficient method of data collection and because it provides researchers with an easy way to replicate research and to share data.

\section{1-139 Tsang, Wai King (City U. of Hong Kong) and Wong, Matilda. Giving grammar the place it} deserves in process writing. Prospect (Macquarie U., Sydney, Australia), 15, 1 (2000), 34-45.

This paper deals with the role of grammar in a process writing approach. It reports on the effectiveness of a 14-week writing improvement workshop at tertiary level focusing, with two emphases, on grammar use: (1) to deal with grammar explicitly in class with teacher supervision; and (2) to read widely for a broad exposure to the language system. In alternate weeks, students read newspaper and magazine extracts, completed a corresponding reading/writing worksheet, and answered a quiz on common errors they revised on their own in the previous week. The teacher gave feedback immediately after sentences were made, and a cloze was completed in the worksheet. In lessons following reading/writing worksheets and common errors quizzes, the teacher gave feedback on the extended writing submitted at the end of the previous lesson, and students practised process writing on a topic. Results showed that, though there was no significant improvement at the sentence level in terms of production, students developed an awareness of correct grammar forms and were more able to recognise the correct versions of sentences. It was also suggested that, in extended writing, they could write with greater readiness and more mature syntax in terms of longer average $\mathrm{T}$-units, more accurate $\mathrm{T}$-units, and more complex sentences.

\section{1-140 Way, Denise Paige (Dorchester School}

District Two, Summerville, USA; Email: dway@ dorchester2. k12.sc.us), Joiner, Elizabeth G. and

Seaman, Michael A. (U. of South Carolina, USA). Writing in the secondary foreign language classroom: the effects of prompts and tasks on novice learners of French. The Modern Language Journal (Malden, MA, USA), 84, 1 (2000), 171-84.

This study investigated the effects of three different writing tasks (descriptive, narrative, and expository) and three different writing prompts (bare, vocabulary, and prose model) on 937 writing samples culled from 330 novice learners enrolled in 15 classes of Levels 1 and 2 high school French. In order to assess the quality, fluency, syntactic complexity, and accuracy of the writing samples, the researchers employed four evaluation methods: holistic scoring, length of product, mean length of T-units, and percentage of correct T-units. Results indicate that the descriptive task was the easiest and the expository task the most difficult. The prose model prompts produced the highest mean scores, and the bare prompts produced the lowest mean scores. Based on these findings, the researchers question whether the description of a novice writer in the ACTFL [American Council on the Teaching of Foreign Languages] Proficiency Guidelines (1986) should be used as a blueprint for curriculum development and textbook construction for secondary novice foreign language learners.

01-141 Ying Lao, Christy (Columbia U., USA) and Krashen, S. (U. of Southern California, USA). The impact of popular literature study on literacy development in EFL: more evidence for the power of reading. System (Oxford, UK), 28, 2 (2000), $261-70$.

There is compelling evidence that reading, especially free voluntary reading, has a strong positive impact on 
second language development. Studies carried out in the informal environment have shown that those who report more free reading achieve higher levels of competence in second languages. In the present study, university-level English as a Foreign Language (EFL) students in Hong Kong who participated in a popular literature class that emphasised reading for content and enjoyment, including some self-selected reading, made superior gains on measures of vocabulary and reading rate, when compared to students enrolled in a traditional academic skills class. Eighty-eight per cent of the literature students felt that what they learned from the course would help them in other university courses, but only $12 \%$ of the traditional academic skills students had this opinion about their class. These results are seen as consistent with previous studies showing that meaningful reading is an important source of literacy competence.

\section{Language testing}

\author{
01-142 Kenyon, Dorry M. (Center for Applied \\ Linguistics, Washington, USA; Email: \\ dorry@cal.org) and Tschirner, Erwin (Universität \\ Leipzig, Germany; Email: erwin.tschirner@t- \\ online.de). The rating of direct and semi-direct oral \\ proficiency interviews: comparing performance at \\ lower proficiency levels. The Modern Language \\ Journal (Malden, MA, USA), 84, 1 (2000), 85-101.
}

As states and universities institute oral proficiency requirements with vast numbers of students to be tested, there is a need to investigate effective alternatives to the ACTFL (American Council on the Teaching of Foreign Languages) Oral Proficiency Interview (OPI) that allow group testing. This article reports on a study comparing student performances and test reliabilities for the German Speaking Test (GST) developed by the Center for Applied Linguistics, a semi-direct tapemediated oral proficiency test, and the ACTFL OPI. Both the GST and a German OPI were administered as final oral exams to a randomly selected group of 20 students (out of a total of 59) enrolled in a fourth-semester German course at a large Midwestern university. The OPI levels of the students tested ranged from Novice High $(n=5)$ and Intermediate Low $(n=9)$ to Intermediate $\mathrm{Mid}(n=6)$. At these three levels, final ratings on the GST and the OPI agreed with each other perfectly in $90 \%$ of the cases. There were only two one-step disagreements, both involving students who were rated Novice High on the ACTFL OPI, but who received other ratings on the GST. Although the results indicated a high score equivalency between ACTFL proficiency ratings obtained on both tests, this study is seen as underscoring the pressing need for double ratings and arbitration procedures in high stakes testing situations.
01-143 Krajnović, Marta Medved (Filozofski fakultet, Zagreb U., Croatia). Učeničke strategije i testovi stranih jezika. (Learner strategies and foreign language tests.] Strani Jezici (Zagreb, Croatia), 28, 3/4 (1999), 149-55.

This article is an attempt to connect two important aspects of foreign language learning and teaching: learner strategies and testing. It discusses the importance of test-taking strategies research in validating language tests and gaining a deeper insight into learners' knowledge. The author describes the most widely used research methodology - test-takers' verbal or written reports, and recent research in test-taking strategies used for different testing techniques (multiple-choice, cloze-tests, c-tests, oral interviews). The possible pedagogical implications of the research results are also pointed out.

\section{1-144 Krause, Wolf-Dieter and Sändig, Uta} (Universität Potsdam, Germany). Zur Effektivierung von Leistungskontrollen und Tests für die Überprüfung der Kommunikationskompetenz im Fremdsprachenunterricht (unter Berücksichtigung von ersten Ergebnissen des europäischen Kooperationsprojektes ECCELLENTT). [Increasing the effectiveness of performance controls and tests for checking communicative competence in foreign language teaching (taking into account the preliminary results of the European co-operative project ECCELLENTT).] Fremdsprachen und Hochschule (Bochum, Germany), 57 (1999), 88-116.

When the setting and development of tests is not merely concerned with linguistic knowledge, but is to be evaluated on the basis of language-communicative ability, the task becomes a complex one. This article deals with the aims of such tests and how they should be created accordingly, focusing in particular on task type and the corresponding test process in evaluating receptive and productive language activities in an FL context (here, German as a foreign language). Such considerations are set against the background of the preliminary results of the European co-operative project ECCELLENTT (Evaluation of Communicative Competence in European Language Learning Encompassing New Testing Technologies) which sets out seven criteria for the setting and evaluation of tests: objectivity, authenticity, reliability, validity, practicability, impact and involvement/interactiveness. Task types and corresponding tests are discussed in the light of each of these criteria. Two sample tests are included in the appendix.

01-145 Laurier, Michel (U. of Montreal, Canada; Email: laurierm@SCEDU.Umontreal.ca). Can computerised testing be authentic? ReCALL (Cambridge, UK), 12, 1 (2000), 93-104.

The concept of authenticity first appeared with the development of the communicative approach. More 